Rhode Island College

Digital Commons @ RIC

Master's Theses, Dissertations, Graduate

Master's Theses, Dissertations, Graduate Research and Major Papers Overview

Research and Major Papers

$1-1-2014$

\title{
Nurses' Perceptions of Nurse Staffing and the Impact on Patient Falls
}

Kristin J. Henry

Rhode Island College

Follow this and additional works at: https://digitalcommons.ric.edu/etd

Part of the Nursing Administration Commons, and the Other Nursing Commons

\section{Recommended Citation}

Henry, Kristin J., "Nurses' Perceptions of Nurse Staffing and the Impact on Patient Falls" (2014). Master's Theses, Dissertations, Graduate Research and Major Papers Overview. 238.

https://digitalcommons.ric.edu/etd/238

This Major Paper is brought to you for free and open access by the Master's Theses, Dissertations, Graduate Research and Major Papers at Digital Commons @ RIC. It has been accepted for inclusion in Master's Theses, Dissertations, Graduate Research and Major Papers Overview by an authorized administrator of Digital Commons @ RIC. For more information, please contact digitalcommons@ric.edu. 
(Date)

\title{
NURSES' PERCEPTIONS OF NURSE STAFFING AND THE IMPACT ON PATIENT FALLS
}

\author{
by \\ Kristin J. Henry \\ A Major Paper Submitted in Partial Fulfillment \\ of the Requirements for the Degree of \\ Master of Science in Nursing \\ in \\ The School of Nursing \\ Rhode Island College \\ 2014
}




\begin{abstract}
Patient falls contribute to unnecessary injury and incapacitation for patients and are also a major source of stress for the nurses caring for patients who fall. Hospitals are no longer being reimbursed for extended hospital stays related to injuries caused by patient falls and action is needed to decrease such events. Nurse staffing has been shown to play a critical role in determining the incidence of patient falls, with better nurse staffing decreasing the likelihood of a patient falling. The purpose of this study was to determine nurses' perceptions of nurse staffing and its impact on the incidence of patient falls. The methodology included a short, self-administered survey developed by the researcher. Nurses answered 15 questions related to the number of patients they cared for, number of patient falls, and factors that could influence falls. Nurses who completed the survey reported caring for between 2-7 patients on their last shift and reported between 0-2 falls on their assignment within the previous three months. Nurses indicated that factors such as admission and discharge activity, the number of available staff on the unit, and the acuity of patients on the unit impacted patient falls. Further research is needed to determine the relationship between nurse staffing and the incidence of patient falls. Advanced Practice Registered Nurses (APRNs) are in an ideal position to participate in research related to this topic as well to advocate for nursing's role in preventing patient falls.
\end{abstract}




\section{Table of Contents}

Table of Contents...................................................9age

Background and Statement of the Problem...................................

Review of the Literature ..............................................4

Theoretical Framework...............................................14

Methods.............................................................. 17

Results............................................................20

Summary and Conclusions..........................................27

Recommendations and Implications for Advanced Nursing Practice.............31

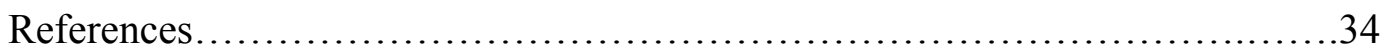

Appendices........................................................ 39 


\section{Background and Statement of the Problem}

Falls in the hospital setting range from four to 14 falls per 1000 patient days; approximately $12 \%$ of patients will fall at least once during their hospitalization (Kalisch, Tschannen, \& Lee, 2012). Injuries, including fractures, occur in up to $25 \%$ of in-hospital falls; the average hospital stay for patients who fall increases by six to 12 additional days, costing up to $\$ 13,316$ more than the hospital stay for those patients who do not fall. As of October 1, 2008, the Centers for Medicare and Medicaid Services (CMS) deemed inhospital falls as preventable, non-reimbursable events. This means that CMS no longer covers the costs associated with in-hospital falls (Bouldin et al., 2013).

Patient falls have the potential to be not only extremely harmful, and even incapacitating for patients, but can also cause major stress in nurses. Nurses must determine how to get the patient off the floor, consider the extent of injury, document the event accurately, and be aware of possible legal allegations (Rush et al., 2008). The issue of appropriate and safe staffing levels also has a profound effect on nurses' physical and emotional health. One study found that higher patient-nurse ratios increase nurses' emotional exhaustion, feelings of burnout, and job dissatisfaction (Aiken, Clarke, Sloane, Sochalski, \& Silber, 2002). A survey by the American Nurses Association (ANA, 2011) of over 4,600 registered nurses revealed that $56 \%(n=2,576)$ reported having experienced a musculoskeletal injury or pain that was caused or made worse by their job. In the same survey, $70 \%$ of nurses $(n=3,220)$ ranked stress and overwork as their top health and safety concern, with a disabling lifting injury $(n=2,760)$ at $60 \%$ as a close second. 
The National Database of Nursing Quality Indicators (NDNQI, 2012) recognized patient falls as a nurse sensitive quality indicator. A survey of nurses $(n=305)$, physicians $(n=49)$ and pharmacists $(n=25)$ conducted at 29 small, rural hospitals found that $96 \%$ of nurses $(n=293)$ and $90 \%$ of physicians $(n=44)$, pharmacists $(n=22)$, and hospital administrators $(n=22)$ believed prevention of harm to patients in the hospital was primarily the responsibility of nurses (Cook, Hoas, Guttmannova, \& Joyner, 2004). According to a report published by the Agency for Healthcare Research and Quality (AHRQ), better patient outcomes are sensitive to nurse staffing ratios, although a causal relationship is currently unclear (Kane, Shamliyan, Mueller, Duval, \& Wilt, 2007). Aiken et al. (2002) found the odds of death due to a medical complication related to issues such as falls were increased by $7 \%$ for each additional patient added to a nurse's workload. The issue of nurse staffing and its impact on patient safety is so significant that the ANA is supporting federal legislation for safe nurse staffing levels with the Registered Nurse Safe Staffing Act of 2013 (H.R. 1821). Thus far, seven states have passed legislation for safe nurse staffing levels based on recommendations by the ANA (ANA, 2013).

Although a significant amount of research has revolved around examining the relationship between increased nurse staffing ratios and the incidence of patient falls, evidence is lacking in determining how nurses perceive staffing to affect the number of falls on their units. Advanced practice nurses (APNs) need to be knowledgeable about patient safety as they are ultimately responsible and accountable for safe patient care. With new mandates for Medicare reimbursement, it is critical for the APN to collaborate 
with interdisciplinary team members to mitigate patient safety issues such as falls, as well as advocate for safe environments for patients. Therefore, the purpose of this study was to describe nurses' perceptions of the impact of nurse staffing levels on the incidence of patient falls. 


\section{Review of the Literature}

The researcher, using Ovid SP and CINAHL (Cumulative Index to Nursing and Allied Health Literature) databases conducted a comprehensive search of the literature published between 2001 and 2013. Keywords used to conduct the search included patient falls, nurse staffing, nurses' perceptions, patient safety, nurse-patient ratios, Donebedian, Donebedian's structure, process, outcomes, Donebedian's framework.

\section{Nurses' Perceptions of Patient Safety}

Patient safety is a major concern in today's healthcare system. Much research has focused on this topic, but only a few studies have examined how nurses perceive patient safety. Ramanujam et al. (2008) conducted a survey of nurses in two U.S. hospitals which revealed that several factors negatively influenced nurses' perceptions of patient safety. These factors included education level (-0.177), experience level (-0.009), full time vs. part time status (-0.116), work volume (-0.034) and work demands $(-0.061)$. Higher education, more experience, full-time status, and increased work volume and work demands increased nurses' negative perceptions of patient safety. Narrative comments in this survey included "It would be safer for the patient if the nurse had a lighter load" and "Nurses are exhausting themselves in an effort to make health care safe" (p. 148). Lack of literature related to nurses' perceptions of how staffing can affect patient falls highlights the need for further research on this critical topic. 


\section{Falls: Definition and Overview}

The AHRQ (2013) defined a fall as "an unplanned descent to the floor, with or without injury." The National Database for Nursing Quality Indicators (NDNQI, 2012) added the adjectives "assisted" and "unassisted" to this definition of falls. An unassisted fall is one in which "the patient is found on the floor." An assisted fall is one in which "a staff member is with the patient at the time of the fall and attempts to minimize impact by assisting or lowering the patient to the floor." Repeat falls are defined as "more than one fall in a given month by the same patient on a unit." This does not include falls that occurred outside the hospital prior to admission. Falls with injury include falls that result in some degree of sustained injury or trauma that is directly related to the fall. This can include anything from minor injury such as lacerations or bruises, to extreme injury, leading to death.

\section{Falls in Acute Care Hospitals: Incidence}

In the United States (U.S.), each year, between 700,000 and 1,000,000 people experience a fall while in the hospital. It is estimated that one-third of these falls are

preventable (AHRQ, 2013). A study completed in a 1,300 bed academic medical center reviewed patient falls on seven specialty units and found that medical and neurology units had the highest rate of patient falls at 6.12 falls per 1000 patient days and the highest patient-nurse ratio; the medical unit had an average of 6.5 patients per nurse $(\mathrm{p}<$ $0.001)$ and the neurology unit had an average of 5.3 patients per nurse $(\mathrm{p}<0.001)$. Orthopedics had 0.80 falls per patient day and 5.0 patients per nurse $(\mathrm{p}<0.001)$ (Hitcho et al., 2004). Another study, which did include critical care units, found that fall rates 
were highest on medical units and lowest on critical care units (Dunton, Gajewski, Taunton, \& Moore, 2004).

Tzeng (2010) conducted a study on four inpatient units including medical beds (n $=109)$, surgical beds $(\mathrm{n}=53)$, and medical-surgical beds $(\mathrm{n}=34)$, in an acute care hospital in Michigan to determine the incidence of falls attributed to toileting activities such as getting in and out of bed to use the bathroom. A total of 547 falls occurred during the time of the study, of which $58 \%$ occurred with patients on medical units $(\mathrm{n}=$ $63), 18.6 \%$ with patients on surgical units $(n=10)$ and $23 \%$ with patients on medicalsurgical units $(n=8)$. Approximately $45 \%$ of falls in this study were related to toileting activities $(\mathrm{n}=247)$, which is an important aspect of nursing care and requires adequate nurse staffing to accomplish safely.

In a recent study (Bouldin et al, 2013) of 6,100 medical, surgical, and medicalsurgical units in 1,263 different hospitals, researchers reported a total of 315,817 falls (3.56 falls/1000 patient days), $26.1 \%$ of which resulted in injury to the patients. The fall rate was found to be higher for patients in medical units (4.03 falls/1000 patient days), followed by medical-surgical units (3.62 falls/1000 patient days), and finally by surgical units (2.76 falls/patient days). Intensive care, step down, and rehabilitation units were not included.

\section{Nurse Staffing}

Nurse staffing is often defined as Staff Mix or Total Nursing Care Hours Per Patient Day (ANA, 2014). The ANA defined Staff Mix as the percent of registered nursing care hours among the total of all nursing care hours including RNs, LPNs, and 
unlicensed personnel, which included certified nursing assistants (CNAs). Total Nursing Care Hours Per Patient Day is defined as the total number of productive hours worked by all nursing staff with direct patient care responsibilities in a patient day (ANA, 2014). The AHRQ (2004) also included the Nurse-Patient Ratio as a measure of nurse staffing which is defined as the ratio of nurses to patients multiplied by the ratio of productive nursing hours per 24 hours. The NDNQI (2012) defined Skill Mix as the percent of registered nursing care hours to the total nursing care hours provided by all staff including LPNs and unlicensed personnel. It also uses the same definition as the AHRQ for Total Nursing Care Hours Per Patient Day.

Nurse staffing levels have been an issue during the last several decades as the nursing shortage has continued to increase. The Bureau of Labor and Statistics (2012), predicted a nationwide RN job vacancy of 1.2 million nurses by the year 2020 . This forecast indicates that nurse staffing will continue to pose a complex issue for hospitals throughout the country.

\section{Nurse Staffing and Patient Falls}

The Institute of Medicine (IOM, 2003) released a report called Keeping Patients Safe, which identified that "the typical work environment of nurses is characterized by many serious threats to patient safety" (p. 3). When the report was released in 2004, it revealed that nurses had lost trust in both nursing and hospital administrators, nurses felt that their voices were not being heard, and that they were not being encouraged and supported in their orientation or continuing education needs. Nurses also reported long work hours and short staffing, with some nurses reporting caring for as many as 7 to 12 
patients in one shift (IOM, 2003). Three years later, nurses again reported not having enough support from their managers and not having adequate staffing (Lake \& Friese, 2006).

Much of the literature has established a relationship between nurse-staffing and patient safety outcomes. Dunton et al. (2004) conducted a study to examine the relationship between nurse staffing (Nursing Hours Per Patient Day, Skill Mix) and falls in acute care facilities. Their study concluded that up to 15 hours of nursing care per patient day had a significant relationship with decreased falls on step-down units $(-0.0527, \mathrm{p}<0.01, \mathrm{n}=$ 393), medical units $(-0.0829, \mathrm{p}<0.001, \mathrm{n}=439)$, and medical-surgical units $(-0.0643, \mathrm{p}$ $<0.001, \mathrm{n}=602)$. The surgical units did not reveal significance $(-0.0286, \mathrm{n}=317)$. There was no significant relationship between staffing ratios and number of falls when the patient received more than 15 hours of nursing care. They also identified that the percentage of nursing care hours provided by RNs was related to decreased falls on stepdown $(-0.0088, \mathrm{p}<0.01, \mathrm{n}=393)$ and medical $(-0.0059, \mathrm{p}<0.05, \mathrm{n}=439)$ units. The study indicated a need for further research to determine why there was no correlation between staffing level and number of falls on surgical units.

Krauss et al. (2005) performed a case control multivariate study of 98 patients who experienced a fall as compared with 318 control patients who did not fall. Their data revealed that an increased patient to nurse ratio was significantly related to an increased risk of falling. It was found that patients of nurses who were caring for more than 5 patients had a 2.6 times $(n=98)$ greater risk of falling than when nurses had 5 or fewer patients (Krauss et al., 2005). 
Lake, Shang, Klaus and Dunton (2010), conducted a survey of 5,338 nursing units in 636 hospitals in several different states in order to examine the relationship between nurse staffing, RN composition, hospital Magnet status, and number of patient falls. The number of RN hours per patient per day was related to decreased falls on ICUs $(0.967, \mathrm{p}$ $<0.001 \mathrm{n}=1,281$ ), but not on other nursing care units. Since Magnet hospitals tend to have a higher percentage of RN hours, there was also a five percent decreased fall rate in Magnet hospitals versus non-Magnet hospitals. Because these data emerged from ICUs that have higher patient acuity and higher nurse staffing levels, these findings may not be generalized to other types of nursing care units.

A recent study in Taiwan studied the relationship between nurse workload and nursingsensitive patient safety outcomes, including falls. The study found that the odds ratio, or the odds/risk that a patient will fall, of a patient falling was 5.14 with a nurse-patient ratio of $1:>11$ $(\mathrm{p}=0.004), 1.51$ for nurse-patient ratios of $1: 10-11(\mathrm{p}=0.004)$ and 3.59 with a nurse-patient ratio of $1: 8-9(\mathrm{p}=0.007)$. The odds ratio of a patient falling was only 1.00 when the nurse-patient ratio was $<7$ (Liu, Lee, Chia, Chi, \& Yin, 2012). The results of this study implied that the risk of a patient falling generally increases as more patients are added to a nurse's workload. Patients were less likely to fall if the nurse was caring for less than 7 patients.

Results of the Dunton et al. (2004) study were consistent with other studies. Patrician et al. (2011) studied nurse staffing in relation to adverse events at the shift level in 13 military hospitals and analyzed their results by unit type. They found that the percentage of RNs in relation to the percentage of unlicensed personnel was significant in decreasing falls in medical surgical $(1.11, \mathrm{n}=57,913$ shifts $)$ and critical care units $(1.20$, 
$\mathrm{n}=35,570$ shifts). There was a $15-51 \%$ increase in falls resulting in injury for every decrease of 1 hour of nursing care depending on the unit type. Total Nursing Care Hours Per Patient Shift (NCHPPS) showed odds ratios of falls were 1.07 for medical/surgical units, 1.09 for step-down units, and 1.14 for critical care units for each one-hour decrease in NCHPPS.

Staggs, Knight, \& Dunton, (2012) studied nursing unit and hospital characteristics as predictors of fall rates on 1502 nursing units from 248 US hospitals. Results showed that both $\mathrm{RN}$ skill mix $(\mathrm{t}=-1.90)$ and average $\mathrm{RN}$ tenure on the unit $(\mathrm{t}=-1.45)$ were negatively associated with falls $(\mathrm{p}<0.001, \mathrm{n}=1,502)$. Choi \& Boyle, (2013) examined the relationship between $\mathrm{RN}$ job satisfaction and falls in a study of 2,763 acute care nursing units and determined that increased RN skill mix, or the proportion of RNs to total staff, $(\operatorname{IRR}=0.997, \mathrm{p}<0.05, \mathrm{n}=2,763)$ and $\mathrm{RN}$ tenure on unit $(\mathrm{IRR}=0.983, \mathrm{p}<$ $0.001, \mathrm{n}=2,763$ ) were related to a decreased incidence of falls. This translated to a decreased incidence of falls when there were more RNs working on the unit with a larger portion having worked on the particular unit for a long time.

Staggs \& Dunton (2014), examined the relationship between RN Hours Per Patient Day and unassisted falls on 8,069 nursing units in 1,361 acute care hospitals. This study revealed that higher $\mathrm{RN}$ hours per patient day were associated with decreased unassisted fall rates $(\mathrm{n}=2567, \mathrm{p}=0.015)$ on medical-surgical units. All unit types except for rehabilitation units including step-down $(\mathrm{n}=1557, \mathrm{p}=<0.001)$, medical $(\mathrm{n}=$ $2010, \mathrm{p}=<0.001)$, medical-surgical $(\mathrm{n}=2567, \mathrm{p}=<0.001)$, and surgical $(\mathrm{n}=1395, \mathrm{p}=$ 
$0.005)$ were noted to have increased unassisted fall rates with higher non-RN hours per patient day.

Kalisch \& Williams (2009) described missed care as any nursing care or interventions that were either delayed, not completed, or entirely omitted such as ambulation. A study of 3432 nurses and 980 CNAs in 11 acute care hospitals used the Missed Nursing Care Survey. This study reported that the number of hours per patient day (the more hours worked by RNs and nursing assistants) was associated with decreased patient falls $(\mathrm{r}=-0.36, \mathrm{p}<0.01)$ and the more nursing care that was missed increased the fall rates $(\mathrm{r}=0.30, \mathrm{p}<0.01)$ (Kalisch et al., 2012).

Studies have revealed mixed results in terms of the relationship between number of nursing staff and number of patient falls. Patrician et al. (2011) conducted a study which concluded that increasing the percentage of RNs on a unit is associated with a decreased number of falls. However, a study by Potter, Barr, McSweeney, \& Sledge (2003) studied the same question and concluded that there was no significant relationship between the percentage of RN nursing care hours and number of patient falls $\left(\mathrm{R}^{2}=0.012\right.$, $p<0.05)$. Their study did find a significant positive relationship between total hours of nursing care and falls $\left(\mathrm{R}^{2}=0.170, \mathrm{p}<0.05\right)$. Total hours of care included hours provided by all nursing personnel, licensed and unlicensed.

A study of 77 medical, surgical and obstetric units in 19 teaching hospitals throughout Ontario, Canada found that nurse staffing was not significantly associated 
with falls $(\mathrm{T}=-1.86)$, and average number of nursing care hours experienced was not related to falls $(\mathrm{T}=-1.61)$ (McGillis-Hall, Doran, \& Pink, 2004).

\section{Nurses' Perceptions of Safe Staffing}

There have been studies that described nurses' perceptions of adequate, safe staffing. One study found a significant association between perceptions of adequate staffing with better nursing skill mix, or the proportion of total nursing staff who were RNs $(r=0.204, p=0.25)$. Perceptions of less adequate staffing had a significant inverse association with nurses' workload $(\mathrm{r}=-0.221, \mathrm{p}=0.015)$ and large unit size $(\mathrm{r}=-0.231, \mathrm{p}$ $=0.011$ ). Patient technology, which was defined as the acuity level (degree of illness, amount of nursing care required to care for the patient) of the patients, was significantly associated with nurses' perceptions of less adequate staffing $(r=-0.198, p=0.030)$ (Mark, 2002). Kalisch, Friese, Choi, and Rochman, (2011) surveyed nurses on 92 medical-surgical, intermediate care, and rehabilitation nursing units in 11 hospitals and reported that nurses perceived higher staffing adequacy on units with a greater proportion of nurses with BSN degrees or higher $(r=0.21, p=0.040)$; units with inadequate assistive personnel perceived lower staffing adequacy $(b=-0.50, p<0.01)$. This study also reported that perception of adequate staffing was correlated with nurse-reported work-load on last shift $(\mathrm{r}=-0.384, \mathrm{p}=0.000)$.

\section{Summary}

Falls are a cause of serious injury, debilitation, and even death for hospitalized patients as well as a cause of injuries and significant stress in nurses. Nurses are susceptible to emotional exhaustion, burnout and job dissatisfaction as they strive to 
prevent patient falls while working within minimal staffing situations. Many findings from the literature review revealed a link between nurse staffing and its effect on patient falls, though little research has focused on how nurses perceive the impact of staffing on the risk for patient falls. The current increased cost of healthcare highlights the need for continued research to develop cost-effective ways of decreasing patient falls and improving patient outcomes. As CMS does not reimburse the hospitals for extended stays related to a patient's fall, prevention of a fall is critical to reducing healthcare costs to hospitals. APRNs have a responsibility to investigate the possible relationship between nurse staffing and the incidence of patient falls. This study proposes a first step by investigating nurses' perceptions of staffing levels and the relationship to nurses' perceptions of patient falls. 


\section{Theoretical Framework}

The framework that guided this research study is Donebedian's Structure, Process, and Outcomes Model, which defines three categories related to quality of care. Structure pertains to the setting in which care occurs; the components of structure are facilities, equipment, personnel, and organization of healthcare providers. Process is the way in which care is provided; components of care are patient as well as medical and nursing activities related to patient care. Outcome is defined as the impact that care has on patients. Components of outcomes include patient knowledge, adverse patient events, and nursing-sensitive patient outcomes such as falls, pressure ulcers, and urinary tract infections (Donebedian, 1988).

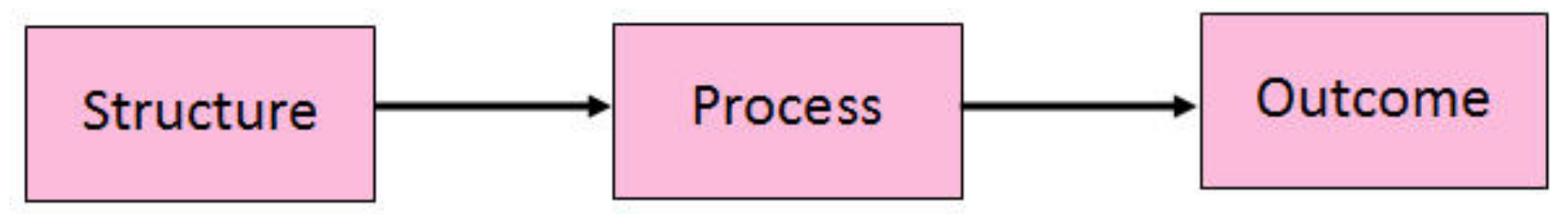

- Material resources

- Human resources

- Organizational structure

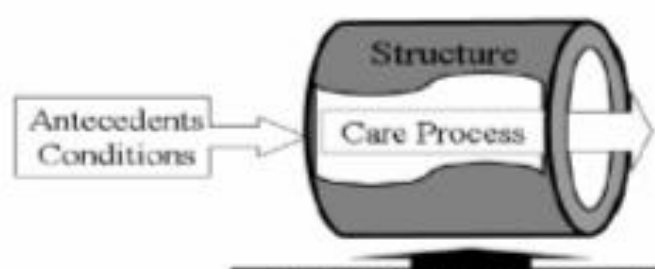

Patients and families

- Seeking or carrying out care

Provider

- Diagnosis

- Treatment

Patient Safety Management
- Health status c patients and population

- Improvements in patient's knowledge an behavior

- Patient and family satisfaction

Figure 1. (AHRQ, 2005) 
The National Database of Nursing Quality Indicators (NDNQI) uses Donebedian's Model of Quality Care as a framework for research and data collection related to nursing-sensitive indicators. The NDNQI includes the number of available nursing staff, skill levels, and educational or certification status of nursing staff as characteristics of "structure". The term "process" is used within NDNQI to refer to nursing care such as assessments and interventions, while "outcome" refers to nursingsensitive indicators such as patient falls and pressure ulcers (Montalvo, 2007).

Donebedian's Model has provided the theoretical framework in a variety of studies. Aiken et al (2002) reported the effects of nurse staffing (structure) on burnout and patient mortality (outcome). They found that each additional patient which is added to a nurse's workload increased the risk of patient mortality by $7 \%$ (Aiken et al, 2002). Duffield et al. (2007) also examined the effect of nurse staffing and nurse workload on patient outcomes by using the Donebedian Model to describe the relationship. Some of the structure variables included nursing hours per patient day, percent of RNs compared to unlicensed staff, and patient turnover. Outcome variables included length of stay, failure to rescue, falls, and medication errors. Results suggested that an increased proportion of RNs to total nursing staff was directly associated with a decreased incidence of failure to rescue $(n=43, p=0.01)$. The Donebedian Model also provided the theoretical basis for a study that explored the concept of missed nursing care which was defined as the aspects of nursing care that are missed when nurse-to-patient staffing levels are low, in which there are less nurses to care for patients. That study found that when nursing care (such as ambulation, toileting, and call light response) is missed due to 
poor staffing and higher patient to nurse ratios, an increased number of patient falls occurred $(\mathrm{n}=3432, \mathrm{r}=0.30, \mathrm{p}=<0.01)$ (Kalisch et al., 2012).

For the purpose of this study, the researcher examined if and how nurses' perceptions of nurse staffing (structure) correlate to nurses' perceptions of patient falls (outcome). The Donebedian Model, particularly the areas of structure and outcome, provided the framework to describe nurses' perception of nurse staffing and patient falls on their units. 


\section{Methods}

\section{Purpose}

The purpose of this study was to describe how nurses perceive that nurse-patient staffing ratios impact the number of patient falls that occur on their units.

\section{Design}

The research study employed a cross-sectional descriptive design. The key variable was nurses' perceptions of how nurse-staffing impacts patient falls.

\section{Sample}

Registered nurses from three medical-surgical units at a large, urban, level 1 trauma center located in the Northeastern part of the U.S. comprised the convenience sample for this study. The inclusion criterion for participation was to be a registered nurse, with any level of experience or education on any shift, on any of the three nursing units. To raise awareness of and recruit participants for the study, the researcher posted flyers regarding the survey on the units two weeks prior to the administration of the survey. The nurses agreed to participate and implied consent through their review of an informational letter, which explained the risks and benefits of participation in the study, and completion of the anonymous survey.

\section{Site}

The study site provided three units for data collection that had similar patient acuity and nurse-patient ratios. Permission to conduct the study was obtained from the Chief Nursing Officer of the hospital (Appendix A) as well as the facility's Institutional 
Review Board, and the Rhode Island College Institutional Review Board. The facility was easily accessible to the researcher and cost was minimal.

\section{Procedures}

The researcher developed and posted IRB approved flyers on the three designated nursing units describing the research project and the purpose of the survey. The flyer included the researcher's contact information in case of questions that needed clarification before administration of the survey. Two weeks after the posting of the flyers, the researcher placed surveys (Appendix C) in the break room of each designated nursing unit. The surveys were kept in an envelope that was attached to a large poster to attract attention. Attached to the front of each survey was an IRB approved informational letter (Appendix B) explaining the risks and benefits of participation in the study. Completion of the survey implied that the nurse had read and reviewed the letter of agreement and gave consent for participation.

Participants were asked to place completed surveys in a sealed drop-box provided in the break room of each nursing unit. In order to protect the identity and anonymity of the participants no identifying or demographic information was requested from participants and the researcher had sole access to the sealed box. Participants were given two weeks to complete surveys and place them in the sealed drop-box, after which the researcher collected the drop-boxes from each unit.

In order to protect privacy and confidentiality after collection of the data and analysis of the results, all survey data and results will be stored in a locked office as provided by Cynthia Padula, the principal investigator, to which only the researcher will 
have access. All data will be kept for a minimum of three years in this fashion, after which all information will be destroyed appropriately.

\section{Measurement}

The survey was a short, 15- item self-administered questionnaire consisting of three multiple-choice questions, four open-ended questions, and eight questions offering a Likert response. When a thorough review of the literature located no established tool to measure nurses' perceptions of staffing and patient falls, the necessary survey was developed by the researcher through modification of the MISSCARE Survey (Kalisch \& Williams, 2009) and the Practice Environment Scale of the Nursing Work Index [PESNWI] (Lake, 2002). Permission to use the tools with modifications was obtained from both authors. Before administration as a data collection tool for this study the resulting document was piloted on a small group of registered nurse peers not actively employed on the study units to ensure that it was useful for the purpose of this study.

\section{Data Analysis}

After collection of the surveys from the nursing units, the researcher reviewed the questionnaires and entered data into the Microsoft Excel for analysis of results. To maintain confidentiality of the participants in the study as well as the nursing units as a whole, the researcher entered survey data using random identification codes. The researcher analyzed the results of the study using basic descriptive statistics available in Microsoft Excel. 


\section{Results}

\section{Nursing Characteristics and Patient Flow}

After the researcher posted 100 surveys, 20 participants returned completed surveys; sample size was $20(\mathrm{n}=20)$. The nurses who completed surveys identified their level of education, years of experience as an $\mathrm{RN}$, and shift primarily worked. These characteristics of the sample are summarized in Figures 2, 3, and 4.

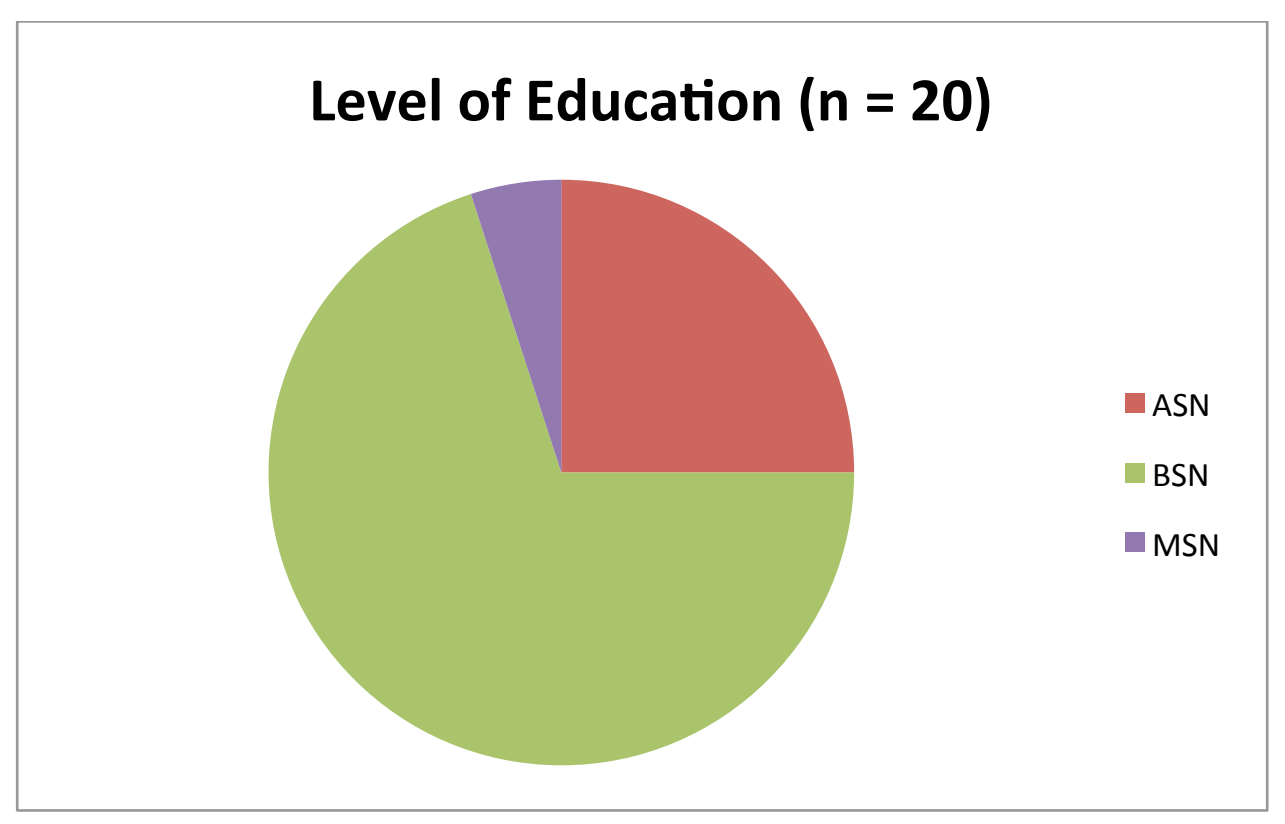

Figure 2. Level of education of sample population reported as highest earned degree.

Significant findings from Figure 2 show that $70 \%(n=14)$ of nurses surveyed held BSN (Baccalaureate) degrees and 25\% $(n=5)$ held ASN degrees (Associate's). One nurse held an MSN (Master's of Science in Nursing) degree $(n=1)$. None of the nurses in the sample $(\mathrm{n}=0)$ held a diploma in nursing. 


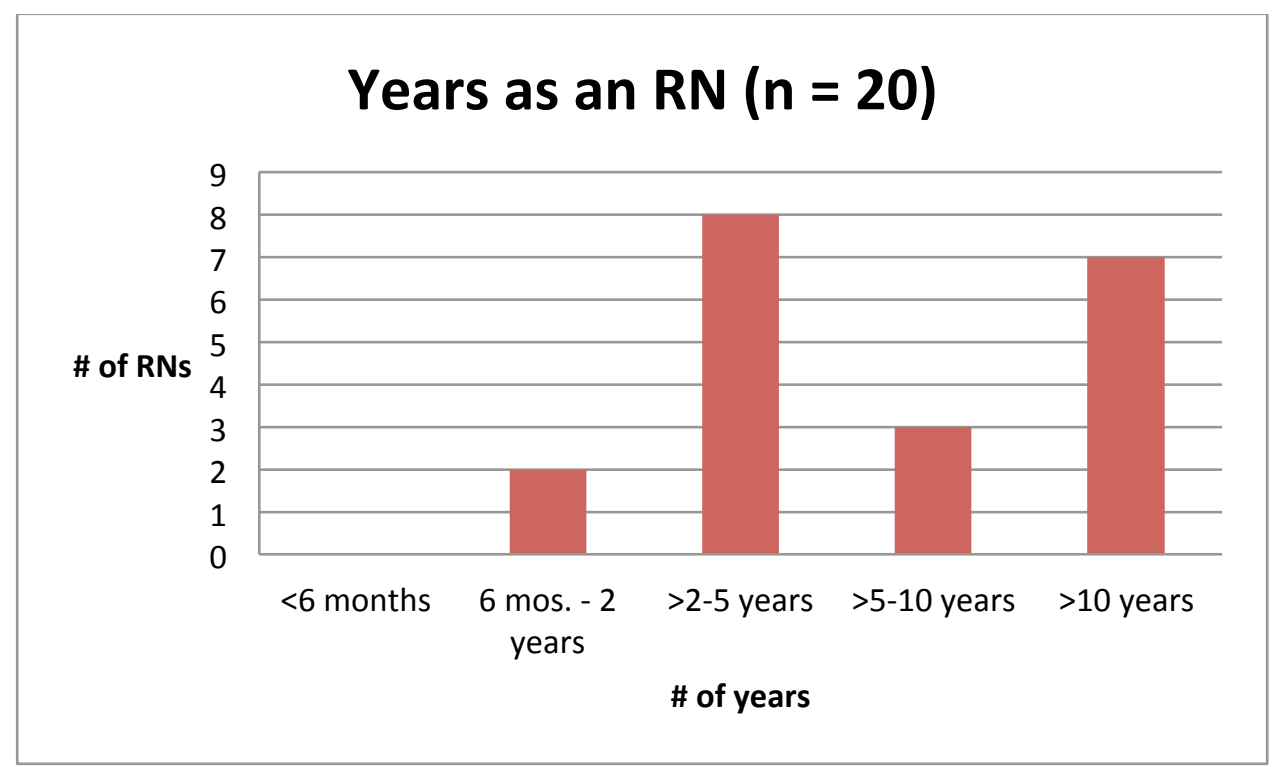

Figure 3. Years of experience as an RN reported in years.

All of the nurses in the sample $(n=20)$ had worked as RNs for at least 6 months, with a majority of them working as RNs for $2-5$ years $(n=8,40 \%)$ and greater than 10 years $(n=7,35 \%)$. 


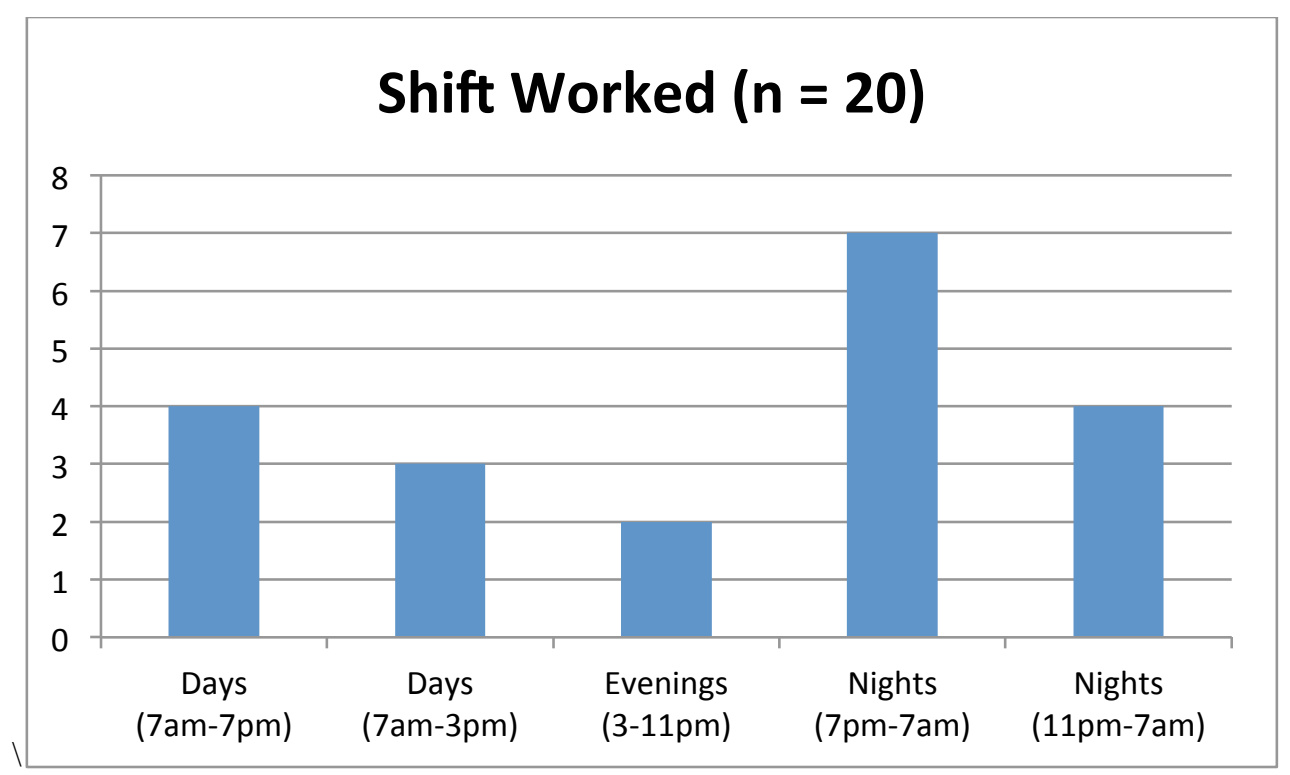

Figure 4. Shift worked by sample population reported by duration of shift.

Figure 4 presents the distribution of the respondents by shift worked. Eleven nurses (55\%) worked 12 hour shifts and nine nurses (45\%) worked 8 hour shifts. Seven nurses worked day shift (35\%), two nurses worked evening shift (10\%) and eleven nurses worked night shift (55\%). The largest percentage of nurses was found on the night shift $(\mathrm{n}=11,55 \%)$

Table 1 summarizes patient flow data on the three units studied on the nurses' current or last worked shift. It also summarizes the number of nurse reported falls during a three-month period prior to survey administration. 
Table 1

Patient Flow on Last or Current Shift; Nurse Reported Falls in Last Three Months (n= 20)

\begin{tabular}{|l|r|r|r|r|}
\hline Patient Flow Data & Mean & Median & Mode & \multicolumn{1}{|l|}{ Range } \\
\hline \# of Patients Cared For & 5.1 & 5 & 5 & $2-7$ \\
\hline Admissions/Transfers & 1.25 & 1 & 1 & $0-4$ \\
\hline $\begin{array}{l}\text { Discharges } \\
\text { \# Falls in Last 3 months ( } \mathrm{n}=\end{array}$ & 0.6 & 0 & 0 & $0-3$ \\
\hline 17) & 0.85 & 1 & 0 & $0-2$ \\
\hline
\end{tabular}

Nurses reported caring for a mean of 5.1 patients on their current or last shift, with a range between 2 and 7 patients. A mean of 1.25 admissions/transfers were reported with a range of 0 to 3; a mean of 0.6 discharges with a range 0 to 3 were also reported. There were a total of 17 falls reported by nurses during a three-month period; eleven nurses $(55 \%)$ reported having at least one of their patients fall in the prior three months. The mean fall rate was 0.85 falls per nurse.

\section{Nursing Care Activities}

Nurses were asked to respond to how often they were able to participate in nursing care activities using a 5 point Likert scale from never (1) to always (5). A majority of the nurses' surveyed reported that they were frequently $(n=12)$ or always (n $=6$ ) able to respond to patient call lights within 5 minutes of the patient putting the call light on. Nurses also reported being frequently able to assist with toileting needs within 5 minutes $(n=12)$. A large proportion of nurses believed that they were only able to 
ambulate their patients, as ordered, occasionally $(n=9)$ or rarely $(n=6)$. None $(n=0)$ of the nurses who completed surveys reported being unable to assist with daily nursing care activities. Nurses' responses to nursing care activities are highlighted in Figure 5 and a summary of the central values of nursing care activities is provided in Table 2 .

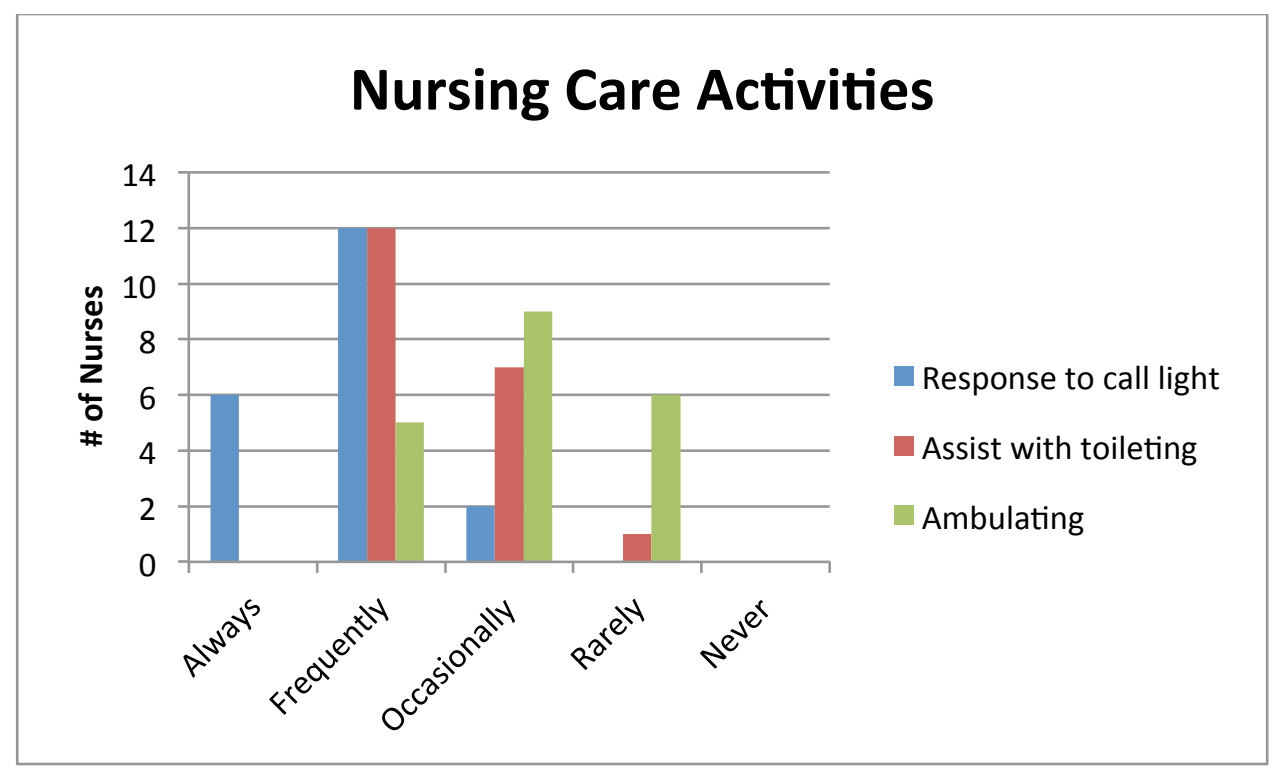

Figure 5. Nursing care activities reported in how often respondents felt they could accomplish activities

Table 2

Nurse Reported Ability to Assist with Nursing Care Activities; Reported in Measures of Central Tendency $(n=20)$

Nursing Care Activities

Response to call light

Assist with toileting

Ambulation

\section{Mean}

4.2

3.55

2.95

\section{Median}

Median

4.2

4

Mode

4

\section{Range Standard Deviation}

$4 \quad 3-5$

2-4

2-4 


\section{Nurses' Perceptions of Impact of Staffing on Patient Falls}

Nurses who participated in the study strongly agreed that the total number of staff including RNs and nursing assistants combined $(n=16)$, total number of RNs $(n=12)$, total number of assistive personnel (nursing assistants) $(n=18)$, patient acuity $(n=20)$, and admission/discharge activity $(\mathrm{n}=15)$ impacted patient falls on their units. Figure 5 and Table 3 further describe these data.

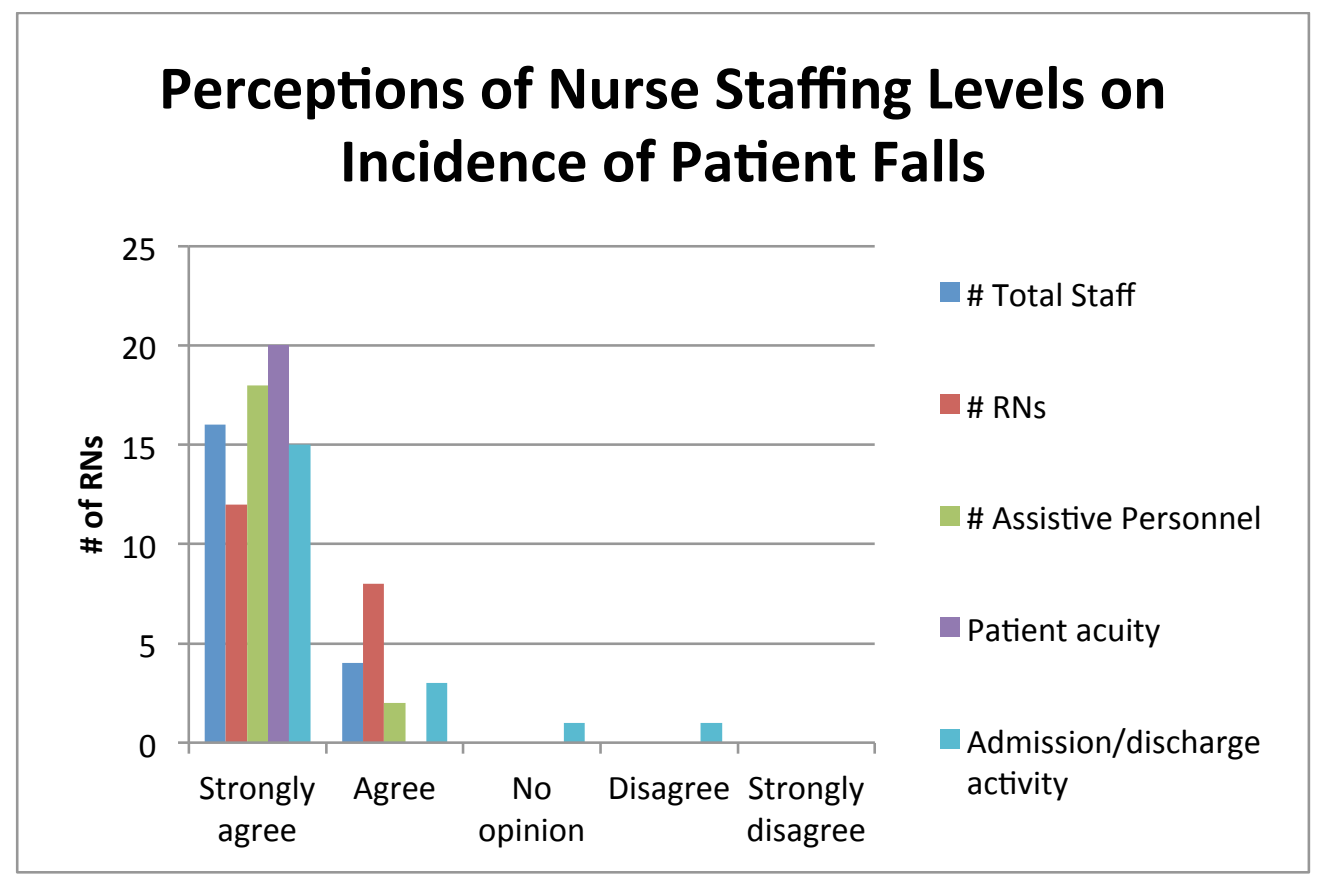

Figure 6. Nurses' perceptions of nurse staffing levels on incidence of patient falls. 
Table 3

Nurses' Perceptions of Impact of Nurse Staffing Levels on Incidence of Patient Falls; Reported in Measures of Central Tendency

\begin{tabular}{|l|r|r|r|r|r|}
\hline Impact of Staffing on Falls & Mean & Median & Mode & Range & $\begin{array}{l}\text { Standard } \\
\text { Deviation }\end{array}$ \\
\hline \# Total Staff & 4.8 & 5 & 5 & $4-5$ & 0.41 \\
\hline \# RNs & 4.6 & 5 & 5 & $4-5$ & 0.5 \\
\hline \# Assistive Personnel & 4.9 & 5 & 5 & $4-5$ & 0.31 \\
\hline Patient acuity & 5 & 5 & 5 & 5 & 0 \\
\hline Admission/discharge activity & 4.6 & 5 & 5 & $2-5$ & 0.82 \\
\hline
\end{tabular}

The above section highlights relevant findings of the research study, including characteristics of the nurses that were surveyed, data on patient flow and nursing activities, and nurses' perceptions of nurse staffing levels and its impact on the incidence of patient falls. 


\section{Summary and Conclusions}

In-hospital patient falls are debilitating events to both patients and nurses; nurses play a critical role in preventing falls and maintaining patient safety. A hallmark report on nurse staffing and patient safety concluded that the risk of patient mortality due to events such as falls increased by $7 \%$ for each additional patient added to a nurse's workload (Aiken et. al, 2002). Although seven states have thus far passed legislation on safe nurse staffing levels, nurses continue to work on seemingly understaffed units with high patient to nurse ratios (ANA, 2013). This, furthermore, increases the risk of adverse patient events, such as falls.

The aim of this study was to describe nurses' perceptions of the impact of nurse staffing levels on the incidence of patient falls. A thorough, comprehensive review of the literature between the years 2001 and 2013 was completed. The theoretical framework, which guided the study, was the Donebedian model of structure, process and outcomes (Donebedian, 1988). IRB approval was obtained from Rhode Island College as well as the facility of study. Permission to conduct the study was obtained from the Chief Nursing Officer (CNO) at the facility.

A review of the literature did not locate an established data collection tool for use in this study. This lead to a researcher-developed a survey based on the modification of two established tools after receiving permission from the authors of each tool. Two weeks prior to survey administration, IRB approved flyers, which described the project, were placed on the nursing units where data were to be collected. IRB approved surveys 
were then placed on three nursing units at a large, urban, level 1 trauma center. Attached to each survey was an informational letter of agreement; after reading and completing surveys, nurses' consent to participate was implied. Completed surveys were collected in sealed drop-boxes to which the researcher had sole access. During the two week collection period, a total of 20 completed surveys were collected. The data were entered in to Microsoft Excel and analyzed using basic descriptive statistics included in the program.

Data collected from this study revealed that the majority of the nurses who completed surveys were baccalaureate prepared $(\mathrm{BSN})$ nurses $(\mathrm{n}=14)$, worked the night shift $(n=10)$, and had been an RN for at least two years $(n=18)$. Nurses reported caring for 2-7 patients with an average of 5.1 patients on their most recently worked shift. A total of 17 falls were reported on the care nurses' assignments over a 3 month period by participating nurses, with an average patient fall rate of 0.85 falls per nurse over 3 months. Nurses reported having an assigned patient experience a fall 0-2 times during the prior 3 months. Nurses reported that they were often able to assist with nursing care activities such as responding to call light, toileting needs and ambulating patients as ordered. Nurses perceived that staffing characteristics, including total number of staff on the unit, number of RNs, number of assistive personnel, patient acuity and admission/discharge activity impacted the occurrence of patient falls.

Results of this study were consistent with several other studies, including a study by Ramanujam et al., (2008), which concluded that nurses with higher education and 
experience were more likely to perceive patient safety as compromised when reduced staffing levels led to increased work demands. Nurses in the current study agreed that the total number of staff working on the unit impacted the incidence of patient falls, in which less staff on the unit increases the incidence of patient falls. These results were consistent with the results of a study by Kalisch et al., (2012), which also determined that falls were more likely to occur when there was less staff working on the unit.

Results from a study by Patrician et al., (2011) determined that a higher percentage of RNs compared to the percentage of nursing assistive personnel was more likely to decrease falls; similar results were found by Choi \& Boyle (2013). In contrast the above studies, the current study found that more nurses believed that falls were more likely to decrease when there was an increased percentage of assistive personnel vs. RNs working on the unit.

Limitations in this study include the small, convenience sample size $(n=20)$ which affects the extent to which results can be generalized. Additional staff education and recruiting regarding the study could have increased participation and provided a larger sample size. The limited time frame for the collection of the study and the sample site of only three nursing units in one large, urban hospital does not allow for generalization of results.

The tool used for data collection was modified from two existing tools; validity and reliability have not yet been established for this new tool, which makes it difficult to determine validity and reliability of the results found in this study. Since the number of 
falls was nurse reported and not concluded from a database of falls records, the number of falls in the study may not be completely accurate and could skew results. In future studies, obtaining data on the actual number of falls from a database would be beneficial in increasing the validity of the results. Respondents also could have self-selected that they were most interested in preventing patient falls by indicating more patient falls. The descriptive nature of this study is limited to perceptions of appropriate and safe staffing levels as a factor to decrease falls; further research is needed on this topic.

The results of this study have described nurses' perceptions of nurse staffing and its impact on patient falls. Although nurses reported that they were frequently able to assist in nursing activities, the results of the survey revealed other factors that impact falls; these factors are the number of nursing and assistive staff on the floor, patient acuity, and high admission/discharge activity. 


\section{Recommendations and Implications for Practice}

Advanced practice registered nurses (APRNs) are in an ideal position to advocate for and educate nurses regarding safe nurse staffing and improved patient outcomes. The need for APRN-led research related to patient falls and nurse staffing will be critical in the future for improving both patient safety and promoting a culture of safe levels of nursing workloads. The rigorous educational background of APRNs prepares them to participate in and disseminate findings of evidence based research on this topic with the goal of decreasing patient falls. It is of utmost value to the employers of APRNs and RNs, as reimbursement for medical care related to in-patient falls is no longer an option. APRNs can collaborate with other nursing colleagues to advocate for increased patient safety, and in turn decreased health care associated costs.

Although a number of states have already passed legislation on minimum nurse staffing levels, it is crucial that other states follow suit. APRNs, by collaborating with other healthcare professionals and professionals at the local, state or national level, can advocate for these policies and laws, nurses, and patient safety. Policies and procedures should be developed at the institutional level regarding nurse staffing levels required for each type of nursing unit, with a plan which addresses how alterations in patient acuity or nurse workload will affect these staffing guidelines. It is critical that nurses and APRNs act as leaders and role models to effect change in the mindset of stakeholders regarding appropriate nurse staffing to assure achievement of the best outcomes for the patients. 
Although much research has focused on the relationship between nurse staffing and patient safety, there is a need for larger, quantitative studies that establish clear guidelines on what appropriate nurse staffing levels are and how these levels can be established and funded. The costs associated with hiring and training more RNs must be weighed against the costs that hospitals are absorbing due to patient safety events such as falls. APRNs and nurses will be key leaders in establishing the cost effectiveness of hiring more nurses to increase staffing versus patient safety events. They will also act as change agents in collaborating with hospital finance professionals, who need to value and acquire a sufficient number of nurses to assure patient safety. APRNs will play an active role as leaders in conducting and disseminating this research and in implementing appropriate strategies to promote better nurse staffing and improved patient care. APRNs are in an ideal position to educate nurses, other healthcare providers, as well as the public on the importance of safe nurse staffing. By becoming involved in professional organizations, promoting and disseminating research and evidence based practice, and facilitating change in policy, APRNs can educate and involve nurses and other healthcare professionals in safe nurse staffing and improved patient outcomes. Engaging consumers and other stakeholders in the process of assuring patient safety is a goal for the APRN, as a leader, to achieve.

In summary, this research study has described nurse staffing and the impact it has on patient falls, but more quantitative research is needed to draw the correlation between nurse staffing patterns and patient falls. APRNs can be key leaders in advancing patient safety through participating in and disseminating evidence based practice related to 
patient falls. Through advocating for the role of nurses' in preventing patient falls at the institutional, local, state and national levels, and educating all members of the healthcare team, APRNs can make a difference. The patients' and their families will benefit from this effort to improve patient safety. All of these considerations can be sources for future research in this important area of nursing practice. 


\section{References}

Agency for Healthcare Research and Quality [AHRQ]. (2004). Hospital Nurse Staffing and Quality of Care. Research in Action, (14). Retrieved from www.nursingworld.org

AHRQ. (2005). Medical team training. Retrieved from www.ahrq.gov

Agency for Healthcare Research and Quality [AHRQ]. (2013). Preventing falls in

hospitals; a toolkit for improving quality care. Retrieved from www.ahrq.gov

Aiken, L. H., Clarke, S. P., Sloane, D. M., Sochalski, J., \& Silber, J. H. (2002). Hospital nurse staffing and patient mortality, nurse burnout, and job dissatisfaction. JAMA, 288(16), 1987-1993.

American Nurses Association. (2011). ANA 2011 Health and Safety Survey. Retrieved from www.nursingworld.org

American Nurses Association. (2013, May 8). Registered nurse safe staffing bill introduced in congress. Retrieved from www.nursingworld.org

American Nurses Association. (2014). ANA Indicator History. Retrieved from www.nursingworld.org

Bouldin, E. L., Andresen, E. M., Dunton, N. E., Simon, M., Waters, T. M., Liu, M., ... Shorr, R. I. (2013). Falls among adult patients hospitalized in the United States: Prevalence and trends. Journal of Patient Safety, 9(1), 13-17.

Bureau of Labor and Statistics'. (2012). Employment Projections 2010-2012. Retrieved from http://www.bls.gov/new.release/ecopro.t06.htm 
Choi, J., \& Boyle, D. K. (2013). RN workgroup job satisfaction and patient falls in acute care hospital units. Journal of Nursing Administration, 43(11), 586-591. Doi: 10.1097/01.NNA.0000434509.66749.7c

Cook, A. F., Hoas, H., Guttmannova, K., \& Joyner, J. C. (2004) An error by any other name. American Journal of Nursing, 104(6): 32-43.

Donebedian, A. (1988). The quality of care; How can it be assessed? JAMA, 260(12), 1743-1748.

Duffield, C., Diers, D., O’Brien-Pallas, L., Aisbett, C., Roche, M., King, M., Aisbett, K. (2011). Nursing staffing, nursing workload, the work environment and patient outcomes. Applied Nursing Research, 24, 244-255. doi:10.1016/j.apnr.2009.12.004

Dunton, N., Gajewski, B., Taunton, R. L., \& Moore, J. (2004). Nurse staffing and patient falls on acute care hospital units. Nursing Outlook, 52, 53-59. http://dx.doi.org/10.1016/j.outlook.2003.11.006

Hitcho, E. B., Krauss, M. J., Birge, S., Dunagan, W. C., Fischer, I., Johnson, S., ... Fraser, V. J. (2004). Characteristics and circumstances of falls in a hospital setting. Journal of General Internal Medicine, 19, 732-739.

Institute of Medicine. (2003). Keeping patients safe. Retrieved from The National Academic Press: Retrieved from http://books.nap.edu/openbook.php?record_id=10851\&page=R1 
Kalisch, B. J., Friese, C. R., Choi, S. H., \& Rochman, M. (2011). Hospital Nurse Staffing; Choice of measure matters. Medical Care, 49(8), 775-779. Retrieved from www.lww-medicalcare.com

Kalisch, B. J., Tschannen, D., \& Lee, K. H. (2012). Missed nursing care, staffing, and patient falls. Journal of Nursing Care Quality, 27(1), 6-12. http://dx.doi.org/10.1097/NCQ.0b013e318225aa23

Kalisch, B. J., \& Williams, R. A. (2009). Development and psychometric testing of a tool to measure missed nursing care. Journal of Nursing Administration, 39(5), 211219.

Kane, R. L., Shamliyan, T., Mueller, C., Duval, S., \& Wilt, T. J. (2007). Nurse staffing and quality of patient care: Evidence report/technology assessment No. 151. (Prepared by Minnesota Evidence-based practice Center). Retrieved from http://www.ahrq.gov

Krauss, M. J., Evanoff, B., Hitcho, E., Ngugi, K. E., Dunagan, W. C., Fischer, I., ... Fraser, V. J. (2005). A case-control study of patient, medication, and care-related risk factors for inpatient falls. Journal of General Internal Medicine, 20, 116-122. http://dx.doi.org/10.1111/j.1525-1497.2005.40171.x

Lake, E. T. (2002). Development of the Practice Environment Scale of the Nursing Work Index. Research in Nursing and Health, 25(3), 176-188.

Lake, E. T., \& Friese, C. R. (2006). Variations in nursing practice environment. Nursing Research, 55(1), 1-9. 
Lake, E. T., Shang, J., Klaus, S., \& Dunton, N. E. (2010). Patient falls: association with hospital Magnet status and nursing unit staffing. Research Nursing Health, 33(5), 413-425.

Liu, L., Lee, S., Chia, P., Chi, S., \& Yin, Y. (2012). Exploring the association between nurse workload and nurse-sensitive patient safety outcome indicators. The Journal of Nursing Research, 20(4), 300-308. http://dx.doi.org/10.1097/jnr.0b013e3182736363

Mark, B. A. (2002). What explains nurses' perceptions of staffing adequacy? Journal of Nursing Administration, 32(5), 234-242.

McGillis-Hall, L., Doran, D., \& Pink, G. H. (2004). Nurse staffing models, nursing hours, and patient safety outcomes. Journal of Nursing Administration, 34(1), 41-45.

Montalvo, I. (2007). The National Database of Nursing Quality Indicators (NDNQI). OJIN: The Online Journal of Issues in Nursing, 12(3). Doi: 10.3912/OJIN.Vol12No03Man02

National Database of Nursing Quality Indicators (NDNQI). (2012). Guidelines for data collection on the American Nurses Association's national quality endorsed measures: Nursing care hours per patient day, skill mix, falls, falls with injury. Retrieved from www.nursingquality.org National Database of Nursing Quality Indicators (NDNQI). (n.d.). www.nursingquality.org Patrician, P. A., Loan, L., McCarthy, M., Fridman, M., Donaldson, N., Bingham, M., \& Brosch, L. R. (2011). The association of shift-level nurse staffing with adverse 
patient events. Journal of Nursing Administration, 41(2), 64-70.

http://dx.doi.org/10.1097/NNA.0b013e31820594bf

Potter, P., Barr, N., McSweeney, M., \& Sledge, J. (2003). Identifying nurse staffing and patient outcome relationships: A guide for change in care delivery. Nursing Economics, 21(4), 158-166.

Ramanujam, R., Abrahamson, K., \& Anderson, J. G. (2008). Influence of workplace demands on nurses' perception of patient safety. Nursing and Health Sciences, 10, 144-150. http://dx.doi.org/10.1111/j.1442-2018.2008.00382.x

Rush, K. L., Robey-Williams, C., Patton, L. M., Chamberlain, D., Bendyk, H., \& Sparks, T. (2008). Patient falls: acute care nurses' experiences. Journal of Clinical Nursing, 18, 357-365. http://dx.doi.org/10.1111/j.13.1365-2702.2007.02260.x

Staggs, V. S., Knight, J. E., \& Dunton, N. (2012). Understanding unassisted falls: Effects of nurse staffing level and nursing staff characteristics. Journal of Nursing Care Quality, 27(3), 194-199. http://dx.doi.org/10.1097/NCQ.0b013e318241da2d

Staggs, V. D., \& Dunton, N. (2014). Associations between rates of unassisted inpatient falls and levels of registered and non-registered nurse staffing. International Journal for Quality in Health Care, 26(1), 87-92.

Tzeng, H. (2010). Understanding the prevalence of inpatient falls associated with toileting in adult acute care settings. Journal of Nursing Quality Care, 25(1): 2230.

\section{Appendix A}


Rhode Island Ilospilal

a Li/cspicse Pristher

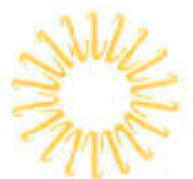

bus tedy" Stcet

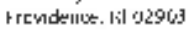

Te qu1 dad-1003

Gekt:er 21,2013

1.ifespai
J]B Administration

I'i wibon It kay concere:

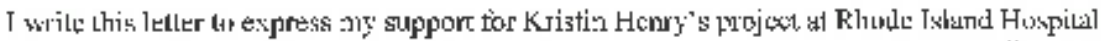

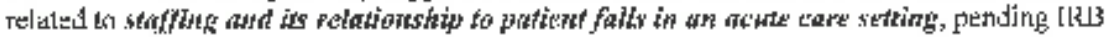
approved.

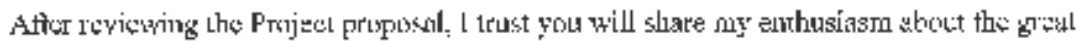

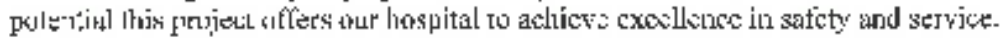

Simesxely.

Bachurile $p$

Burbara P. Rilwy

Str. Vice President \& Chiet Nursing Otficer

\section{Appendix B}




\section{Informational Letter}

I would like to ask you to take part in a research study called "Nurses Perceptions of the Impact of Staffing on Patient Falls". The desired outcomes of this study is to describe whether or not nurses perceive a relationship between staffing levels and patient falls.

Your completing this questionnaire/survey will probably take about 10 minutes of your time. There are 15 questions on this survey for you to answer. To participate, the only request is to complete the attached survey.

There are no questions on this survey that should cause you discomfort. Your taking part in this research questionnaire is entirely voluntary. If you do not want to complete the survey you are free to choose not to fill out the survey.

Your completion of this questionnaire may not benefit you personally. The hope is that completed surveys will provide information and insight as to how nurses perceive staffing to impact patient falls, and in the long run improve nursing practice and patient safety.

All questionnaires for this study will be kept confidential and will not require you to provide any identifying information. The survey is completely anonymous.

If you have any questions about this questionnaire or the research study itself, please feel free to contact Kristin Henry RN on 6A at 444-5761 or personally at 401-742-3627 or email khenry_1910@ric.edu. You can also contact Cynthia Padula, the Principal Investigator for this project, at 793-3617 or cpadula@lifespan.org.

If you have any questions about your rights as a research participant please feel free to call the Lifespan Institutional Review Board subject advocate office at 444-5843.

Thank you very much for your time.

Kristin Henry RN, BSN

Master of Science in Nursing Student

Rhode Island College

\section{Appendix C}




\section{Perceptions of Nurse Staffing and Patient Falls}

For this section, please select the answer which best describes you:

1) What is your highest educational level?
a. Diploma
b. Associate degree (ASN)
c. Bachelors degree (BSN)
d. Masters degree or higher (MSN, PhD, DNP)

2) How many years have you been an RN?
a. Less than 6 months
b. $>6$ months -2 years
c. $>2-5$ years
d. $>5-10$ years
e. $>10$ years

3) Which shift do you work the majority of the time?
a. Days (7am-3pm)
b. Days (7am-7pm)
c. Evenings (3-11pm)
d. Nights (11pm-7am)
e. Nights (7pm-7am)

For the following section, please write the answer in the blank provided:

On your LAST or CURRENT shift:

1) How many patients did you care for during your shift?

2) How many admissions or transfers did you have?

3) How many discharges or transfers off of the unit did you have?

In the last 3 MONTHS:

1) How many times has a patient that you were caring for fallen or been assisted to the floor? 